\title{
Role of Noninvasive Ventilation in the Management of Obese Patients
}

\author{
Saumy Johnson* \\ Department of Respiratory Therapy Sciences, Inaya Medical College, Kingdom of Saudi Arabia
}

Submission: February 06, 2019; Published: March 18, 2019

*Corresponding author: Saumy Johnson, Assistant Professor and Vice Chair, Department of RTS, Inaya Medical College, Riyadh, Kingdom of Saudi Arabia

Keywords: Obesity; Overweight; Adolescents aged; Obesity hypoventilation; Sleep disordered breathing; Weight reduction; Pharmacotherapy; Echocardiographic changes

Abbreviations: WHO: World Health Organization; OHS: Obesity Hypoventilation; BMI: Body Mass Index; PAP: Positive Airway Pressure; CPAP: Continuous Positive Airway Pressure; HRQoL: Health-Related Quality of Life

\section{Mini Review}

National Health and Nutrition Examination Survey data reports that in USA, the prevalence of obesity was 39.8\% in adults and $18.5 \%$ in youth in $2015-2016$. It was also observed that prevalence of obesity was high in middle-aged adults $(42.8 \%)$ than in younger adults $(35.7 \%)$. Obesity in adults is defined as a BMI of greater than or equal to 30 [1]. According to the worldwide reports of obesity by World Health Organization (WHO) in 2016, more than 1.9 billion adults, 18 years and older, were overweight [2]. Of these over 650 million were obese. $39 \%$ of adults aged 18 years and over were overweight in 2016, and $13 \%$ were obese. 41 million children under the age of 5 were overweight or obese in 2016. Over 340 million children and adolescents aged 5-19 were overweight or obese in 2016.

Obesity is a risk factor for many medical disorders. Obesity hypoventilation is a consequence of obesity. WHO has reported that obesity is preventable. Obesity Hypoventilation (OHS) is defined as daytime hypercapnia and hypoxemia $\left(\mathrm{PaCO}_{2}-45 \mathrm{~mm}\right.$ $\mathrm{Hg}$ and $\mathrm{PaO} 2-70 \mathrm{~mm} \mathrm{Hg}$ at sea level) in an obese patient (body mass index [BMI] of $30 \mathrm{~kg} / \mathrm{m}^{2}$ ) with sleep-disordered breathing in the absence of any other cause of hypoventilation [3].

\section{Treatment Options}

In a Meta-analysis by Kaw et al the predictors of chronic hypercapnia in OHS were identified. They are severity of obesity (BMI); severity of OSA, (measured by AHI or hypoxia during sleep) and extent of restrictive chest physiology [4].

In the light of these factors the treatment options should aim at treatment of the sleep disordered breathing, weight reduction and pharmacotherapy.
Treatment of Sleep disordered breathing includes the use of Positive airway Pressure (PAP) therapy. Continuous Positive Airway Pressure (CPAP) is the initial treatment for OHS. There are several studies supporting the use of CPAP in patients with OHS. Howard ME et al conducted a multicentre, double-blind trial with participants randomized to nocturnal Bi-level PAP or CPAP for 3 months. Primary outcome was frequency of treatment failure. Secondary outcomes included health-related quality of life (HRQoL) and sleepiness. The study concluded that in patients who are diagnosed newly with severe OSA, Bi-level PAP and CPAP resulted in comparable improvements in ventilatory failure, HRQoL and adherence [5].

Corral J et al. [6] did research on the Echocardiographic changes with non-invasive ventilation and CPAP in obesity hypoventilation syndrome, where Conventional transthoracic two-dimensional and Doppler echocardiograms were obtained at baseline and after 2 months for patients randomized in to control group ( $\mathrm{n}=70$ - life style modification and Intervention group of NIV ( $n=71)$, CPAP $(n=80)$ to determine the comparative efficacy of 2 months of NIV on structural and functional echocardiographic changes. It was reported that in patients with OHS, NIV was more efficient treatment than CPAP and life style modifications in improving the following parameters such as pulmonary hypertension, left ventricular hypertrophy and functional outcomes. Masa JF et al. [7] in their Pickwick Study found out that NIV and CPAP were more effective than lifestyle modification in improving clinical symptoms and polysomnographic parameters, although NIV yielded better respiratory functional improvements than CPAP. 


\section{Current Research in Diabetes \& Obesity Journal}

A retrospective cohort study of 73 patients by G Gursel et al. [8] where the participants were grouped in to two 1. obese (BMI $>35 \mathrm{~kg} / \mathrm{m}^{2}$ and 2 . non-obese $\left(\mathrm{BMI}<35 \mathrm{~kg} / \mathrm{m}^{2}\right)$, the difference in these two groups in necessary pressure, volume, mode, ventilator and time to reduce $\mathrm{PaCO}_{2}<50 \mathrm{mmHg}$ were explored. Results of this study showed that ICU specialists should be aware that obese patients with acute hypercapnic respiratory failure are more likely to have OSAS / OHS and may need higher PEEP setting and a longer time to reduce their $\mathrm{PaCO}_{2}$ levels than non-obese patients when other NIV setting parameters, such as pressure support levels, modes and tidal volumes, are similar.

Nicolini A et al. [9] in their review suggested that, these patients require higher NIV settings, a longer time to reduce $\mathrm{PaCO}_{2}$ levels below $50 \mathrm{mmHg}$, and they show more often a late but positive response to NIV. OHS patients are often misdiagnosed as having COPD or heart failure in the course of hospital stay for Acute Respiratory Failure. Early determination of OHS can guarantee proper treatment and repeated admissions to ICU. Another study by Ojeda Castillejo E et al. [10] including 2 groups, group1(OHS) Patients with (AHI) $\leq 5$, and group 2, patients with AHI $>5$ found that use of Mechanical ventilation in patients with OHS and /or OSAH is effective and the survival rates are higher.

\section{Summary}

Obesity is a preventable lifestyle disease. OHS is often misdiagnosed or underdiagnosed. OHS can complicate one's ICU course of stay. Early diagnosis and treatment can reduce frequent admissions and cost associated with it. CPAP and BiPAP play an equally important role in the treatment of OHS and large researches are needed to find the differences in the treatment modalities available currently.

\section{References}

1. CM Hales, MD Carroll, CD Fryar, CL Ogden (2017) Prevalence of Obesity Among Adults and Youth: United States, 2015-2016. NCHS Data Brief (288): 1-8.

2. World Health Organization fact sheet.

3. Mokhlesi B, Kryger MH, Grunstein RR (2008) Assessment and management of patients with obesity hypoventilation syndrome. Proc Am Thorac Soc 5(2): 218-225.

4. Kaw R, Hernandez AV, Walker E, Aboussouan L, Mokhlesi B (2009) Determinants of hypercapnia in obese patients with obstructive sleep apnea: a systematic review and meta-analysis of cohort studies. Chest 136(3): 787-796.

5. Howard ME, Piper AJ, Stevens B, Holland AE, Yee BJ, et al. (2017) A randomized controlled trial of CPAP versus non-invasive ventilation for initial treatment of obesity hypoventilation syndrome. Thorax 72(5): 437-444.

6. Corral J, Mogollon MV, Sánchez-Quiroga M, Gómez de Terreros J, Romero A, et al. (2018) Echocardiographic changes with non-invasive ventilation and CPAP in obesity hypoventilation syndrome. Thorax 73(4): 361-368.

7. Masa JF, Corral J, Alonso ML, Ordax E, Troncoso MF, et al. (2015) Efficacy of Different Treatment Alternatives for Obesity Hypoventilation Syndrome. Pickwick Study. Am J Respir Crit Care Med 192(1): 86-95.

8. G Gursel, M Aydogdu, G Gulbas, S Ozkaya, S Tasyurek, et al. (2011) The influence of severe obesity on noninvasive ventilation (NIV) strategies and responses in patients with acute hypercapnic respiratory failure attacks in the ICU: Minerva Anestesiol 77(1): 17-25.

9. Nicolini A, Ferrando M, Solidoro P, Di Marco F, Facchini F, et al. (2018) Non-invasive ventilation in acute respiratory failure of patients with obesity hypoventilation syndrome. Minerva Med 109(6): 1-5.

10. Ojeda Castillejo E, De Lucas Ramos P, López Martin S, Resano Barrios P, Rodríguez P, et al. (2015) Noninvasive mechanical ventilation in patients with obesity hypoventilation syndrome. Long-term outcome and prognostic factors. Arch Bronconeumol 51(2): 61-68.

\begin{tabular}{|l|}
\hline \multicolumn{1}{|c|}{ Your next submission with Juniper Publishers } \\
will reach you the below assets \\
- Quality Editorial service \\
- Swift Peer Review \\
- Reprints availability \\
- E-prints Service \\
- Manuscript Podcast for convenient understanding \\
- Global attainment for your research \\
- Manuscript accessibility in different formats \\
( Pdf, E-pub, Full Text, Audio) \\
- Unceasing customer service \\
Track the below URL for one-step submission \\
https://juniperpublishers.com/online-submission.php \\
\hline
\end{tabular}

